\title{
Identification of a truncated splice variant of IL-18 receptor alpha in the human and rat, with evidence of wider evolutionary conservation.
}

Interleukin-18 (IL-18) is a pro-inflammatory cytokine which stimulates activation of the nuclear factor kappa beta (NF-kB) pathway via interaction with the IL-18 receptor. The receptor itself is formed from a dimer of two subunits, with the ligand-binding IL-18R $\alpha$ subunit being encoded by the IL18R1 gene. A splice variant of murine IL18r1 has been previously described which is formed by transcription of an unspliced intron, forming a 'type II' IL 18r1 transcript, which is predicted to encode a receptor with a truncated intracellular domain lacking the capacity to generate downstream signalling. In order to examine the relevance of this finding to human IL-18 function, we assessed the presence of a homologous transcript by RT-PCR in the human and rat as another common laboratory animal. We present evidence for type II IL18R1 transcripts in both species. While the mouse and rat transcripts are predicted to encode a truncated receptor with a novel 5 amino acid C-terminal domain, the human sequence is predicted to encode a truncated protein with a novel 22 amino acid sequence bearing resemblance to the 'Box 1' motif of the Toll/interleukin-1 receptor (TIR) domain, in a similar fashion to the inhibitory interleukin-1 receptor 2. Given that transcripts from these three species are all formed by inclusion of homologous unspliced intronic regions, an analysis of homologous introns across a wider array of 33 species with available IL18R1 gene records was performed, which suggests similar transcripts may encode truncated type II IL-18R $\alpha$ subunits in other species. This splice variant may represent a conserved evolutionary mechanism for regulating IL-18 activity. 


$\begin{array}{llll}1 & \text { Authors: } & \text { Chris S Booker }{ }^{1} \text {, David R Grattan }{ }^{1} . \\ 2 & \text { Affiliations: } & \text { Centre for Neuroendocrinology } \\ 3 & & \text { Department of Anatomy } \\ 4 & & \text { University of Otago } \\ 5 & \text { PO Box } 913 \\ 6 & \text { Dunedin } 9054 \\ 7 & \text { New Zealand }\end{array}$

8 Corresponding author: C Booker

Email: chris.booker@otago.ac.nz

10

Address: Department of Anatomy

11

12

13

14

15

University of Otago

PO Box 913

Dunedin 9054

New Zealand

Phone: $\quad+6434703445$ 


\section{Introduction:}

Interleukin-18 (IL-18) is a pro-inflammatory cytokine which has been linked with varying degrees of evidence to diseases as diverse as cardiovascular disease (Jefferis et al. 2011), asthma (Ma et al. 2012), inflammatory bowel disease (Siegmund 2010; Matsunaga et al. 2011; Rivas et al. 2011), acute kidney injury (Ho et al. 2010), and type 1 (Smyth et al. 2008) and type 2 diabetes (Thorand et al. 2005; Hivert et al. 2009), either through associations with IL-18 itself or with its receptor or binding protein. The IL-18 receptor belongs to the interleukin1/Toll-like receptor superfamily, and is encoded by two genes - IL18RI and IL18RAP - which encode a ligand-binding subunit (commonly known as IL-18R $\alpha$ ) and accessory protein (IL18R $\beta$ ) subunit, respectively (Dinarello 2009). The ligand-binding subunit, IL-18R $\alpha$, is also capable of binding a related cytokine, IL-37b (also known as IL-1F7b), to exert antiinflammatory effects (Boraschi et al. 2011).

A mouse cDNA library generated by the Mammalian Gene Collection Program (Strausberg et al. 2002) was later found by Alboni et al. to include a cDNA sequence corresponding to a splice variant of IL18r1 (Alboni et al. 2009), formed by inclusion of part of an unspliced intron in the mRNA sequence. Alboni et al. named this variant type II ILI8r1, with the reference sequence inheriting the nomenclature type I $I L 18 \mathrm{r} 1$, and presented evidence for its expression in the mouse brain. The reading frame resulting from inclusion of an unspliced intron introduces a stop codon shortly into the unspliced intron sequence, and this splice variant would therefore be expected to translate into a truncated receptor with intact extracellular and transmembrane domains, but a short cytoplasmic domain lacking the toll/interleukin-1 receptor (TIR) domain characteristic of IL-1 receptor family members. Given evidence suggestive of a role for IL-18 in the pathogenesis of a range of diseases in humans, we experimentally investigated whether a similar splice variant could exist in the human, finding evidence for an equivalent human type II $I L 18 R I$ transcript. Similar results were obtained in the rat, another commonly used laboratory rodent. IL-18 and its receptor are evolutionarily conserved across a wide range of species, and we therefore assessed whether transcription of homologous intron sequences in other species would be expected to generate truncated IL-18R $\alpha$ subunits through assessing the predicted coding sequences of putative type II IL18RI transcripts across a range of species with available $I L 18 R 1$ gene records. These analyses suggest that the generation of truncated IL-18R $\alpha$ subunits through alternative splicing may form a widespread mechanism of regulating IL-18 activity. 


\section{Materials and Methods:}

Ethics statement:

All experimental procedures were approved by institutional ethics committees. The Animal Ethics Committee of the University of Otago, Dunedin, New Zealand, approved experiments involving rats (project number 58/07). For experimental procedures involving human samples, the only subject was the corresponding author (CB) and the research describes experimental work conducted on samples collected from the author. No written consent was obtained. This research was approved by the Human Ethics Committee of the University of Otago, Dunedin, New Zealand (project number 11/153).

Bioinformatics searches for prior evidence of human type II IL18R $\alpha$ : In order to investigate whether an mRNA sequence incorporating intron 8-9 of the human IL18RI reference sequence (Ensembl accession number: ENST00000233957, Genbank: NM_003855.2) had been previously observed, BLAST searches were performed for cDNA or expressed sequence tags showing similarity to a $362 \mathrm{nt}$ portion of the expected nucleotide sequence, covering the first 60 nucleotides of intron 8-9 preceded by the coding sequences of the two upstream exons (GACTCCAGAAGGCAAATGGCATGCTTCAAAAGTATTGAGAATTGAAAATATTGGTG AAAGCAATCTAAATGTTTTATATAATTGCACTGTGGCCAGCACGGGAGGCACAGACA CCAAAAGCTTCATCTTGGTGAGAAAAGCAGACATGGCTGATATCCCAGGCCACGTCT TCACAAGAGGAATGATCATAGCTGTTTTGATCTTGGTGGCAGTAGTGTGCCTAGTGAC TGTGTGTGTCATTTATAGAGTTGACTTGGTTCTATTTTATAGACATTTAACGAGAAGAG ATGAAACATTAACAGGTAACACATATAATGCTGGAATTTCTTACCTTATGTTCTCATTA AGAAATCAGATAAATA) using a blastn search against the nucleotide collection (nr/nt) or expressed sequence tags (est) databases limited to $H$. sapiens. Identified sequences of interest were further evaluated with the 'Mapviewer' tool from NCBI, and performing BLAST alignments against the human IL18RI reference sequence (NM_003855.2/ENST00000233957) and predicted intron insert (intron 8-9 from ENST00000233957) to assess whether these sequences could represent a putative human type II IL-18R $\alpha$ transcript. 
Samples and RNA extraction:

Experimental verification of human and rat type II IL18RI transcripts was performed by RTPCR on human and rat cDNA samples. Human whole blood was obtained from one of the authors (CB), a 32-year-old male of European descent, by venupuncture using a Vacutainer ${ }^{\circ}$ tube containing potassium EDTA from BD Biosciences (USA). RNA was extracted using Zymo Research whole-blood RNA MiniPrep ${ }^{\mathrm{TM}}$ tubes (Zymo Research, USA, catalogue number R1020) without prior lysis of red blood cells, according to manufacturer's instructions. Rat lung samples were obtained from three adult male Sprague-Dawley rats for verifying expression of a rat type II IL18rI transcript, with samples collected fresh after decapitation, placed on dry ice, and transferred to a $-80{ }^{\circ} \mathrm{C}$ freezer until processing. Rats were obtained from the Hercus-Taieri Resource Unit, Dunedin, New Zealand which maintains a colony of Sprague-Dawley rats originally sourced from Charles River, USA (Strain Code: 400, Crl:SD) and were from two litters, with a mean age of 97 days (101, 89 and 101 days, rats $\mathrm{A}, \mathrm{B}$, and $\mathrm{C}$, respectively) and mean weight 459 g (472 g, 443 g, and 461 g, respectively). Rats were housed in group housing with other littermates on 1/4" Bed-o'Cobs ${ }^{\circledR}$ bedding from The Anderson Lab Bedding (The Andersons, Inc. 2012) and fed Rat and Mouse Cubes from Specialty Feeds, Australia (Specialty Feeds Pty Ltd. 2012). Rats had not been involved in previous experimental procedures. Lung samples were homogenized using a Qiagen TissueLyser II (Qiagen, Germany, catalogue number 85300) in QIAzol Lysis reagent (catalogue number 79306) and RNA extracted with Qiagen RNeasy Plus Universal mini spin columns (product number 73404) according to manufacturer's instructions.

\section{$\underline{\text { Reverse transcription: }}$}

Reverse transcription was performed using Superscript ${ }^{\mathrm{TM}}$ III reverse transcriptase (Invitrogen, product number 18080-044) in $20 \mu \mathrm{l}$ reactions containing: $50 \mathrm{ng}$ of random hexamers, approximately $700 \mathrm{ng}$ of total RNA for human blood sample or $3000 \mathrm{ng}$ for rat lung samples, $10 \mathrm{nmol}$ of dNTPs, $0.1 \mu \mathrm{mol}$ of DDT, $4 \mu 1$ of $5 \times$ first strand buffer, 200 units of Superscript $\mathrm{tM}^{\mathrm{TM}}$ III (substituted for DEPC (diethylpyrocarbonate)-treated $\mathrm{H}_{2} \mathrm{O}$ for RT- control samples), 40 units of RNaseOUT ${ }^{\mathrm{TM}}$ (Invitrogen, product number 10777-019) and DEPC-treated $\mathrm{H}_{2} \mathrm{O}$ as needed to complete reaction volumes. Random hexamers, dNTPs, and total RNA were first incubated at $65{ }^{\circ} \mathrm{C}$ for five minutes for annealing of hexamers, and after cooling the remaining reagents were added and samples incubated at $25^{\circ} \mathrm{C}$ for 5 minutes, followed by $50{ }^{\circ} \mathrm{C}$ for 60 minutes, and reactions terminated by incubation at $70{ }^{\circ} \mathrm{C}$ for 15 minutes. For rat samples, following 
108

109

110

111

112

113

114

115

116

117

118

119

120

121

122

123

124

125

126

127

128

129

130

131

132

133

134

135

136

137

reverse transcription 2 units of RNase H (Invitrogen, product number 18021-014) was added and samples incubated for 20 minutes at $37^{\circ} \mathrm{C}$ to remove any remaining complementary RNA.

\section{Primer design:}

Primers were designed to amplify human and rat $I L 18 R 1 / I L 18 \mathrm{r} I$ reference sequence transcripts as shown in Table 1. For amplifying putative type II IL-18R $\alpha$ transcripts, reverse primers were designed against the predicted inserted intron sequences. For rat samples, the same reverse primer as used by Alboni et al. for identifying type II mouse IL-18R $\alpha$ was used (Alboni et al. 2009 ) with three nucleotides modified to match the homologous rat intron sequence. For human samples, the reference ILI8RI sequence (NM_003855.2/ENST00000233957) was truncated to exon 8 and combined with the first $300 \mathrm{nt}$ of intron 8-9 (given that the murine type II IL-18R $\alpha$ sequence incorporates the first $362 \mathrm{nt}$ from the homologous mouse intron) to provide a predicted mRNA transcript sequence, and primers designed using Primer-BLAST (National Center for Biotechnology Information 2010) ensuring a reverse primer was placed in the intron insert (Table 1). For human samples, the reference $I L 18 R I$ sequence was used as positive control to ensure expression of the IL18RI gene could be detected in blood samples. For rat samples, primers against $A c t b$ were included as controls.

\section{$\underline{\text { PCR and gel electrophoresis: }}$}

Polymerase chain reactions for amplification of human transcripts were performed using Platinum ${ }^{\circledR}$ Taq high fidelity and AccuPrime ${ }^{\mathrm{TM}}$ Taq polymerases (Invitrogen, catalogue number 12567-012; henceforth Platinum and Accuprime Taq). Reactions for human samples involving

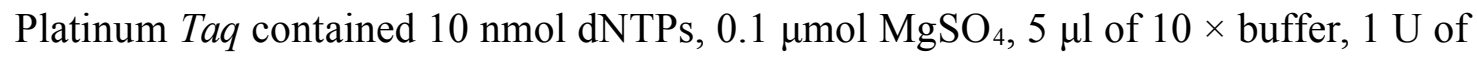
polymerase, approximately $100 \mathrm{ng}$ of cDNA (assuming a $100 \%$ conversion of total RNA to cDNA during reverse transcription), 10 pmol each of forward and reverse primers, and made up to a total volume of $50 \mu \mathrm{l}$ using DEPC-treated $\mathrm{H}_{2} 0$. For reactions involving Accuprime Taq, 5 $\mu \mathrm{l}$ of $10 \times$ 'buffer I', 10 pmol each of forward and reverse primers, approx $100 \mathrm{ng}$ of cDNA, and $2 \mathrm{U}$ of Accuprime Taq were combined with DEPC-treated $\mathrm{H}_{2} 0$ up to a total $50 \mu 1$ volume.

Polymerase chain reactions for rat transcripts were performed in $50 \mu \mathrm{l}$ reactions using Platinum Taq polymerase SuperMix (Invitrogen, catalogue number 12567-012), incorporating $45 \mu \mathrm{l}$ of SuperMix (containing polymerase and dNTPs), $1 \mu \mathrm{l}$ of DEPC-treated $\mathrm{H}_{2} 0,20$ pmol each of forward and reverse primers, and approximately $300 \mathrm{ng}$ of cDNA. 
138

Reverse transcription and PCR reactions were perfomed in polypropylene PCR tubes (Axygen, USA, catalogue number PCR-02D-L-C) and carried out on either a Biometra TProfessional Basic thermocycler (Biometra, Germany, order number 070-701) or MJ Research Minicycler ${ }^{\mathrm{TM}}$ (MJ Research Inc, Watertown, MA, USA, Model PTC-150HB). For amplifications of human IL-18r1 reference and type II transcripts, thermocyclers were set to $94{ }^{\circ} \mathrm{C}$ for 2 minutes for initial denaturing, followed by 35 cycles of $94{ }^{\circ} \mathrm{C}$ for 30 seconds as a denaturing step, $55{ }^{\circ} \mathrm{C}$ for 30 seconds as an annealing step, and $68^{\circ} \mathrm{C}$ for 1 minute for extension. Reactions were terminated with a final extension step of $68^{\circ} \mathrm{C}$ for 3 minutes and cooled to $10{ }^{\circ} \mathrm{C}$ for 3 minutes. For amplification of cDNA from rat samples, thermocycler settings were: $94{ }^{\circ} \mathrm{C}$ for 2 minutes for initial denaturing, followed by 35 cycles of $94{ }^{\circ} \mathrm{C}$ for 30 seconds as a denaturing step, $55{ }^{\circ} \mathrm{C}$ for 30 seconds for primer annealing, and $72{ }^{\circ} \mathrm{C}$ for 1 minute for polymerase extension, followed by a final extension step of $72^{\circ} \mathrm{C}$ for 5 minutes.

Gel electrophoresis of RT-PCR products was performed on $3 \%$ agarose gels (Invitrogen Ultrapure $^{\mathrm{TM}}$ agarose, catalogue number 15510-027) using Qiagen GelPilot DNA loading dye (Qiagen, Germany, catalogue number 239901) and 100 bp DNA ladder (Invitrogen, SKU \#15628-019). Images were captured on a digital camera connected to a Biometra BioDoc Analyzer running BioDoc Analyzer 2.1 software.

\section{PCR product purification and Sanger sequencing:}

PCR products were purified for sequencing using Zymo Research DNA Clean \& Concentrator ${ }^{\mathrm{TM}}-5$ spin columns (Zymo Research, USA, catalogue number D4013) and sequenced at a commercial sequencing service (Genetic Analysis Services, University of Otago (University of Otago 2012)), which performs Sanger sequencing using an ABI 3730x1 DNA Analyser with BigDye ${ }^{\circledR}$ Terminator Version 3.1 Ready Reaction Cycle Sequencing Kits. Chromatograms of sequencing products were used 'as is', with no attempt to manually correct ambiguous reads or base calling errors, and are included in the Supporting Information (Chromatograms S1-S8). Sanger sequencing products and predicted IL-18r1 type II transcript sequences were compared in Geneious Basic (Drummond et al. 2012) using the 'Geneious Alignment' algorithm with default settings (65\% similarity cost matrix, Gap open penalty of 12 , Gap extension penalty of 3, assessed by global alignment with free end gaps). Consensus sequences from forward and reverse primer reads have been submitted to Genbank with 
168 accession numbers KM264374 (Human type II IL18R1 amplified with Accuprime Taq, shown in Figure 2), KM264375 (Human type II IL18R1 amplified with Platinum Taq, shown in Figure 2), KM264376 (Rat type II IL18r1 sequenced from Rat B, shown in Figure S1), KM264377 (Rat type II IL18rI sequenced from Rat C, shown in Figure S1).

Bioinformatics assessment of human TIR domain:

To assess the similarity between the predicted C-terminal portion of human type II IL-18R $\alpha$ and other members of the IL-1 receptor family, protein sequences of the predicted human type IL18R $\alpha$, interleukin-18 receptor 1 precursor (NP_003846.1), interleukin-18 receptor accessory protein precursor (NP_003844.1), interleukin-1 receptor type 1 precursor (NP_000868.1), interleukin-1 receptor-like 2 precursor (NP_003845.2), single Ig IL-1-related receptor (NP_001128526.1), X-linked interleukin-1 receptor accessory protein-like 2 precursor (NP_059112.1), interleukin-1 receptor accessory protein-like 1 precursor (NP_055086.1), interleukin-1 receptor-like 1 isoform 1 precursor (NP_057316.3), interleukin-1 receptor type 2 precursor (NP_775465.1), and interleukin-1 receptor accessory protein isoform 1 precursor (NP_002173.1) were aligned using the MUSCLE (MUltiple Sequence Comparison by LogExpectation) online tool from the European Bioinformatics Institute (European Bioinformatics Institute 2011).

Comparison of human type I IL18RI (reference) and type II sequences:

Given similarities in the predicted amino acid sequence of human type II IL-18R $\alpha$ and the human IL-18R $\alpha$ reference protein sequence, the respective intron and exon nucleotides encoding these amino acids were assessed by EMBOSS (European Molecular Biology Open Software Suite) Water alignment (European Bioinformatics Institute 2011).

Assessment of putative type II IL18RI nucleotide and type II IL-18R $\alpha$ amino acid sequences across multiple species:

In order to assess whether transcription of homologous introns into the IL18RI transcript in other species would also result in truncated receptor, we searched for species with known IL18Rl genes by assessing homology with $H$. sapiens IL-18R $\alpha$ through the Ensembl database. We identified 45 proteins which were further assessed for ambiguous amino acid and nucleotide sequences or other characteristics which would limit their assessment, as detailed in the Table S1. For human IL18R1 transcripts, the Ensembl records IL18R1- 
201/ENST00000233957/ENSP00000233957 were chosen as the comparator as these show 1:1 identity to the NCBI sequences NM_003855.2/NP_003846.1 respectively. Two identified sequences in the Zebra Finch showed homology to the cytoplasmic domains of IL-18R $\alpha$, but sequences lacked any extracellular domains and whether these form functional receptors is unknown; these were therefore excluded from further analysis. Two splice variants were identified in the Tasmanian Devil which arise through the differential use of exons and encode proteins which differ in the cytoplasmic region immediately following the transmembrane domain, similar to the difference between IL-18R $\alpha$ full length proteins and proteins predicted to be encoded by type II IL18RI transcripts in mice, rats and humans. Therefore, these may represent type I (reference sequence) and type II IL18RI splice variants in the Tasmanian Devil and were excluded from further analysis. Similarly, two splice variants were identified in the Turkey which arise through the differential use of exons, however the differences are limited and localized to the extracellular domain of the receptor, therefore only one of these was included in the analysis since both transcripts utilize the same exon structure in the portion which encodes the transmembrane and cytoplasmic domains of the receptor. After exclusions, 34 transcripts and amino acid sequences from 33 species were assessed by multiple sequence alignment to identify introns homologous to those unspliced in type II ILIRRI sequences in the mouse, rat and human, and to predict hypothesized C-terminal domains of type II IL-18R $\alpha$ proteins. Multiple sequence alignments were performed using the MUSCLE tool available from the European Bioinformatics Institute (EBI) (European Bioinformatics Institute 2011) and subsequently passed through the MView tool available from the European Bioinformatics Institute (European Bioinformatics Institute 2011) for ease of visualization. Sequences were assessed through percent identities to human sequences as a reference and outputs are ordered anthropocentrically, i.e. according to similarity to human sequences. For assessment of insertion of an Alu transposable element in primate sequences, the human sequence surrounding the point of Alu insertion was run through the RepeatMasker online tool (Smit et al. 2012) to identify the Alu subfamily inserted, and the $A l u Y$ sequence from the RepeatMasker website (RepeatMasker 2012) used in multiple sequence alignment against desired primate sequences using MUSCLE alignment. An analysis of evolutionary constraint across 29 mammalian species (Lindblad-Toh et al. 2011) includes overlap with 23 of the 33 species analysed here. Regions of high conservation within the human $I L 18 R I$ gene intron 8-9, shown in Figure 6, were identified from the 29 mammals track of the USCS Genome Browser (http://genomewiki.cse.ucsc.edu/index.php/29mammals). 
Nomenclature:

Alboni et al. label the murine IL18rl splice variant incorporating an unspliced intron 'type II' IL18r1, with the reference sequence becoming type I IL18rl (Alboni et al. 2009). This nomenclature is continued here. In order to provide clarity between the splice variant mRNA transcript, which has been experimentally verified in the mouse (Alboni et al. 2009) and in the rat and human in the current work, and the predicted protein sequences encoded by the detected transcripts, throughout the text mRNA transcripts are referred to as either type I or type II IL18R1/IL18r1 (the mRNA products resulting from differential transcription of the IL18R1/IL18r1 gene), with protein sequences as type I or type II IL-18R $\alpha$ (the mature fulllength interleukin-18 receptor alpha reference protein or predicted truncated receptor protein, respectively).

\section{Results and Discussion:}

We examined the Homo sapiens IL18RI gene sequence (ENST00000409599) to first identify whether inclusion of an unspliced intron could give rise to a similarly truncated receptor. Transcription of intron 8-9 of the human IL18RI reference sequence (Ensembl ENST00000233957, Genbank: NM_003855.2; intron 8-9 equivalent to hg19 chromosome 2: $103,006,678-103,010,928)$ would be expected to translate to a protein with a novel 22 amino acid C-terminal followed by a stop codon (Figure 1), and thus generate a type II IL-18R $\alpha$ protein lacking much of the cytoplasmic domain, as predicted for murine type II IL-18R $\alpha$.

In order to investigate whether an mRNA sequence incorporating intron 8-9 had been previously observed, we performed BLAST searches for expressed sequence tags or nucleotide sequences using a $362 \mathrm{nt}$ portion of the expected nucleotide sequence, covering the first 60 nucleotides of intron 8-9 preceded by the coding sequences of the two upstream exons. This revealed three sequences of interest with overlap between exon and intron nucleotides (BG541512.1, BG540341.1, and BG542027.1; Figure 1). Of these, BG540341.1, and BG542027.1 show continuous readthrough of exon-intron sequences and could possibly represent genomic sequences. Of note, BG542027.1 represents a sequence beginning in exon 8 of the human IL18r1 reference sequence and aligns to the first $357 \mathrm{nt}$ of the subsequent intron 8-9, up to nt 436 of BG542027.1, which is a total of 697 nucleotides and is noted to have high quality read up to nt 430 . This aligned intronic region is similar to the length of inserted 
intronic sequence reported for murine type II IL18RI, which incorporates the first $362 \mathrm{nt}$ of the homologous murine intron. BG541512.1, a cDNA sequence from human lung tissue submitted by the Mammalian Genome Collection Project, represented the longest of the identified sequences and showed reasonable similarity to the expected sequence of human type II ILI8RI, incorporating nt 475-1135 of ENST00000233957/NM_003855.2 (representing a continuous read incorporating a portion of exon 3 through exon 8) and approximately 140 bp of intron 8-9 (represented schematically in Figure 1). These data are consistent with the possibility that an alternate transcript incorporating intron 8-9 is present in humans.

In order to experimentally verify whether a human type II ILI8RI transcript could be detected, RT-PCR amplification of cDNA from human blood was performed, utilizing a forward primer placed within exon 4 and a reverse primer in intron 8-9 of ENST00000233957, in order to exclude the possibility of amplifying genomic sequences. Gel electrophoresis of RT-PCR products revealed a band of the expected size for a putative type II IL18RI transcript (Figure 2). Chromatograms showed a sudden drop in read quality around a CAG deletion which has been previously reported in humans (Watanabe et al. 2002), consistent with a heterozygous indel (Bhangale et al. 2005) (See Supplementary Chromatogram files.zip). Despite the drop in read quality, nucleotide sequences in lower quality read portions aligned well with the predicted human type II IL18RI transcript sequence, and non-overlapping regions of high quality read on both sides of the indel from sequencing with forward and reverse primers aligned with the predicted sequence (not shown), demonstrating the RT-PCR product was indeed the predicted human type II IL18RI transcript, and incorporates previously intronic 5' nucleotides of intron 8-9. Assessment of identity with the predicted human type II ILI8RI transcript is shown in Table 2a.

Similar experiments conducted using cDNA isolated from lung tissue of Sprague-Dawley rats showed the presence of a type II IL18rl splice variant transcript in this species as well (Figure S1 and Table 2b). Whereas the mouse (Alboni et al. 2009) and rat type II IL-18R $\alpha$ splice variants are predicted to encode 5 amino acids and result in truncated receptors which lack the TIR domain characteristic of members of the interleukin-1/toll-like receptor superfamily, the predicted sequence of human type II IL-18R $\alpha$ was noted to encode amino acids similar to 'Box 1' of the TIR domain (Dunne \& O'Neill 2003) (Figure 3a). Given the similarity in protein coding sequences, nucleotide sequences from intron 8-9 (encoding the C-terminal of the 
predicted human type II IL-18R $\alpha$ ) were compared with those of exon 9 (which encodes the beginning of the TIR domain in the human type I ILI8RI transcript) by pairwise alignment (Figure 3b). Intron 8-9 exhibits similarity to exon 9, with a number of conserved codons. This suggests these two DNA segments may have arisen through duplication of a previous primordial single region.

IL-18 belongs to the IL-1 family of cytokines, and is highly homologous to IL-1, sharing similarities in processing, receptor function and downstream signalling (Dinarello 1998; Dinarello 2006). In the case of IL-1, a truncated ligand-binding receptor, IL-1R2 (aka IL-1RII), forms a "decoy receptor" lacking the intracellular TIR domain and unable to induce downstream signalling (Colotta et al. 1994). Multiple sequence alignment of members of the human interleukin-1 receptor family (Figure 4) shows that IL-1R2 encodes an amino acid sequence with a C-terminal showing similarities to the 'Box 1' segment of the TIR domain. Similarly, the human type II ILI8RI transcript would be expected to encode a protein with a Cterminal showing similarity to the 'Box 1' segment, terminating just prior to the 'Box 2' segment of the TIR domain, suggesting the predicted type II IL-18R $\alpha$ protein forms an truncated receptor for IL-18, analogous to the IL-1R2 receptor for IL-1.

The truncated inhibitory receptor for IL-1, IL-1R2, is found across a wide range of species, and given a conserved role for IL-18 and its receptor in many species, a similar inhibitory receptor for IL-18 could also be conserved throughout evolution. The previous findings of Alboni et al. showed the existence of a murine type II IL-18R $\alpha$ (Alboni et al. 2009), and our findings of homologous splice variants in human and rat species suggested that insertion of an unspliced intron during transcription of the IL18r1 gene could form a mechanism of generating an inhibitory receptor for IL-18 across a more widespread range of species. We therefore asked whether transcription of homologous intron sequences would be expected to encode truncated splice variants of IL-18R $\alpha$ across species for which gene records for ILI8RI were available.

We identified IL18RI gene sequences for 33 species (Table S1, including human, rat and mouse) from which 34 transcripts and proteins were aligned to identify homologous intron sequences to those experimentally verified to be transcribed in mouse, rat, and human type II ILI8RI splice variants. Alignment of the nucleotide sequences of the preceding exon (equivalent to exon 8 of human $I L 18 R 1$ ) and corresponding protein sequences showed a 
conserved predicted reading frame across species (Figure S2). Analysis of predicted C-terminal amino acid sequences which would be translated from identified intron sequences is shown by multiple sequence alignment in Figure 5. While the predicted mouse and rat protein sequences consist of a short C-terminal tail of 5 amino acids, in many species predicted sequences are a similar length to that predicted in humans, with similarities to the 'Box 1' motif of the TIR domain. As expected based on similarities in intron nucleotide sequences, predicted primate amino acid sequences were similar to the human sequence with the notable exception of the predicted Orangutan sequence, where an adenine in place of a thymine results in an adenosine codon in the Orangutan sequence where other members of the primate family show a stop codon (Figure 6a).

Of note, an Alu insertion is present in the homologous introns of many primate species assessed, being present in the homologous human, orangutan, gibbon, gorilla, chimpanzee and macaque introns, but not in other species assessed. Its presence in this group of primates, but not other primates assessed (Marmoset, Mouse Lemur, Bushbaby or Tarsier) would place its insertion at a last common ancestor in the Catarrhini parvorder, following the separation of the Catarrhini and Platyrrhini parvorders which is estimated to have occurred some 35 million years ago (Mya) (Schrago \& Russo 2003) to 42 Mya (Steiper \& Young 2006), at some stage in the mid- to late-Eocene. Assessment of the human intron sequence with RepeatMasker (Smit et al. 2012) identified the insertion as belonging to the AluY subfamily with 14 transitions, 2 transversions, and one gap of 2 nucleotides. Evident surrounding the complete AluY sequence is a target site duplication (TSD) and oligo(dA)-rich tail from Alu insertion. Upstream from the Alu insertion is a polyadenylation signal (PolyA; AATAAA) which is largely conserved across primates and also across the wider spectrum of species assessed (Figure 6b). The expressed sequence tag BG542027.1 shows alignment of 357 nucleotides into the human intron 8-9 of ENST00000233957, at a point just downstream of this polyadenylation signal, which also aligns with the final nucleotide in the mouse type II IL-18r1 transcript (BC023240) before the polyadenine tail, and thus is likely to represent the transcription termination site of human type II IL18R1. A recent analysis by Lindblad-Toh et al. identified regions of evolutionary constraint across 29 mammalian species (Lindblad-Toh et al. 2011), and revealed five highly-conserved segments present in human IL18RI intron 8-9 (excluding the initial 5' highly conserved intronic nucleotides), four of which map to within or immediately adjacent to the human ILI8RI type II transcript. These represent two regions of overlap with identified stop codon sequences (one of 
which is depicted in Figure 6a), another surrounding the polyadenylation signal (Figure 6b), and a fourth downstream of the predicted transcription stop site, which we hypothesize is likely to play a role in transcription termination. This cross-mammalian conservation is likely to represent selection pressure acting at these loci.

We have found experimental evidence of the existence of a type II ILI8RI transcript in both human and rat species. In both of these cases, as well as the previously reported type II IL $18 \mathrm{r} 1$ transcript in the mouse (BC023240) (Alboni et al. 2009), the splice variants arise from the insertion of unspliced homologous introns. Our analysis of the coding sequences of homologous introns in a wider array of species suggests that this mechanism of generating truncated versions of the IL-18R $\alpha$ subunit could be evolutionarily conserved. Whether or not truncated splice variants are actually transcribed and translated in these species will need to be experimentally verified in each case. However, the regions of conservation identified here and previously by Lindblad-Toh et al. (Lindblad-Toh et al. 2011) demonstrate the existence of selection pressure which is highly suggestive of a wider utilization of similar alternative transcripts beyond the mouse, rat and human.

While predicted rat and mouse type II IL-18R $\alpha$ amino acid sequences consist of a short Cterminal tail immediately following the transmembrane domain, the predicted amino acid sequences in humans and many other species exhibit similarity to the initial region of the TIR domain incorporating the Box 1 motif. In the human (Figure 4) it can be seen that IL-1R2 and the type II IL-18R $\alpha$ splice variant appear to form homologous truncated receptors, with both arising in the ligand-binding subunit of the respective receptor complexes (as opposed to the accessory protein subunits), and both encoding short C-terminal domains with similarity to the 'Box 1' sequence of the TIR domain. Whereas the truncated IL-1R2 receptor is transcribed from a different gene than that encoding IL-1R1, in the case of IL-18R $\alpha$, a similar truncated receptor is predicted to be encoded by the use of a splice variant of the gene encoding the full-length receptor. Previously, IL-18 binding protein (IL-18 BP) has been noted as showing similarity to IL-1R2 in structure and function (Novick et al. 1999; Dinarello \& Fantuzzi 2003), with one study suggesting that they may share evolutionary origins (Watanabe et al. 2005). However, our analysis suggests that, at least in terms of present day predicted protein sequences, IL-1R2 is in fact more similar to the predicted type II IL-18R $\alpha$. The similarity of the coding sequences of exon 9 and intron 8-9 in the human ILI8RI gene sequence (ENST00000233957/NM_003855.2) 
suggests that these gene sequences may have arisen through innovation, amplification and divergence (Bergthorsson et al. 2007) of a what was once a single genetic locus. Given similarities between intron sequences across the range of species assessed here, this explanation seems more likely than convergent evolution, and would also place such a duplication event at a very ancient timepoint in the evolutionary scale.

Exactly what role the Box 1-like motif plays in the relative functions of human versus rodent type II IL-18R $\alpha$ is unknown. In the related IL-1R1, mutations in Box 1 have been shown to disrupt pro-inflammatory signalling (Slack et al. 2000), showing that this conserved domain is critical for normal receptor function. Crystal structures of the related Toll-like receptors 1 and 2 (TLR1/TLR2) and interleukin-1 receptor accessory protein-like 1 (IL1RAPL1) show that the initial Box 1 portion of these receptors forms a $\beta$-strand with the following residues forming an $\alpha$-helix prior the second $\beta$-strand formed by the Box 2 motif (Xu et al. 2000; Khan et al. 2004). Particularly noteworthy are the findings of Khan et al. who assessed the crystal structure of IL1RAPL1 (Khan et al. 2004), another member of the IL-1 family of receptors. In their analysis, constructs of human IL1RAPL1 lacking almost the entire cytoplasmic domain (including only amino acids 1 - 410) transfected into HEK293 cells were still able to activate JNK signalling. These constructs would include almost all of the Box 1 domain, terminating with the residues DAYLS (compare Figure 4), and thus form receptors truncated at a similar point as IL-1R2 and the putative human type II IL-18R $\alpha$. While there is no evidence that IL1RII can induce JNK signalling, a number of studies have shown IL-18 is able to activate JNK signalling (Chandrasekar et al. 2005; Sahar et al. 2005; Seenu Reddy et al. 2010; Amin et al. 2010). The question which then arises is whether a truncated receptor for IL-18 would still be capable of inducing JNK signalling as appears to be the case for a truncated IL1RAPL1 receptor. The work of Chandresekar et al. (Chandrasekar et al. 2005) showed in rat aortic smooth muscle cells that IL-18 induced JNK activation occurs downstream of a variety of intermediate signalling events, including Myd88 activation, and likewise Adachi et al. show a lack of IL-18-induced JNK activation in Myd88-/- cells (Adachi et al. 1998), both providing support for IL-18 activation of JNK occurring downstream of Myd88 recruitment. Whether a truncated IL-18R $\alpha$ subunit would be capable of forming dimers with IL-18R $\beta$ and further complexes with Myd88 is unclear, but seems unlikely given mechanisms of action involving dimerisation of TIR domains. 
Of particular relevance to the results here are recent works investigating the processes controlling differential gene splicing. Given multiple polyadenylation signals are often present within a gene and that transcription occurs in a $5^{\prime}$ to $3^{\prime}$ direction, the question of how longer transcripts are generated when there are coexistent polyadenylation signals at more 5 ' sites has been a topic of investigation. Studies have recently shown that U1 small nuclear RNA (snRNA), which is known for its role in splicing through recognition of 5' splice sites, also plays a key role in suppressing the transcription of shorter transcripts associated with more $5^{\prime}$ polyadenylation signals, and thus regulates transcript length for genes with multiple polyadenylation signals (Kaida et al. 2010; Merkhofer \& Johnson 2012; Berg et al. 2012). Interestingly, autoantibodies to U1 snRNA occur in a number of autoimmune disorders (Breda et al. 2010; Kattah et al. 2010), particularly mixed connective tissue disease and systemic lupus erythematosus, diseases in which altered IL-18 activity or its downstream effector, interferongamma (IFN- $\gamma$ ), have been observed (Bakri Hassan et al. 1998; Bodolay et al. 2002; Favilli et al. 2009). Berg et al. showed that depletion of U1 snRNA through RNA knockdown results in shorter transcripts corresponding to more 5' polyadenylation signals (Berg et al. 2012). Given these findings, autoantibodies to U1-snRNA would be expected to result in an increase in the proportion of type II to type I ILI8RI transcription and a reduction in IL-18 activity (assuming type II IL18RI transcripts form truncated receptors incapable of downstream signalling). In addition, rapidly dividing cells such as those of the immune system exhibit reduced U1-snRNA to transcript ratios (Merkhofer \& Johnson 2012) and shorter transcript lengths. Newly-dividing immune cells may therefore also express higher amounts of type II IL-18r1 transcripts, which could give rise to important differences in IL-18 responsiveness in dividing vs. mature cells. Neoplastic cells are also reknowned for their rate of cell division, and by the same mechanism a reduction in responsiveness to IL-18 through increased type II IL18RI transcription may be of relevance for efforts to treat cancer with IL-18 therapies (GlaxoSmithKline 2008; Srivastava et al. 2010).

Previous research has identified a seemingly paradoxical increase in inflammatory signalling in cells lacking the IL-18R $\alpha$ chain (Lewis \& Dinarello 2006; Nold-Petry et al. 2009). The antiinflammatory cytokine IL-37 is able to bind the IL-18R $\alpha$ chain, and the lack of signalling from IL-37 may underlie the reported phenotype of IL-18R $\alpha$ deficient cells. However, the existence of an inhibitory splice variant of IL-18R $\alpha$ would also raise the possibility that this phenotype 
may derive in part from a lack of type II IL-18R $\alpha$. Whether IL-37 may in fact preferentially bind or act through a truncated IL-18R $\alpha$ subunit is another possibility worth investigating.

The existence of an $A l u$ insert in various primate $I L 18 R I$ gene sequences is in many ways unsurprising, as it is well established that Alu sequences have undergone rapid expansion in the primate family (Batzer \& Deininger 2002; Cordaux \& Batzer 2009; Hwu et al. 1986). The presence of the Alu insert may be of relevance to the regulation of type II ILI8RI transcription in primates; Alu inserts have been shown to contain various regulatory regions, such as retinoic acid receptor motifs (Laperriere et al. 2007; Vansant \& Reynolds 1995) (which are largely conserved in the human IL18RI gene sequence), and various studies suggest a role for Alu insertions in the regulation of gene expression in immune cells (Feschotte 2008; Hambor et al. 1993), with Alu repeats hypothesized as giving rise to evolutionary changes in primates and humans (Cordaux \& Batzer 2009). While a number of studies report a role for Alu insertions in promoter sequences as regulators of gene function (Jacobsen et al. 2009; Pandey et al. 2011; Wang et al. 2011; Ebihara et al. 2002; Le Goff et al. 2003), there is evidence that insertion into other non-promoter regions is also capable of regulating gene transcription. For example, an intronic Alu element in the human CD8 $\alpha$ gene regulates its transcription in T-cells (Hambor et al. 1993), Alu elements in the 3' UTR of genes are involved in a mechanism of Staufen 1 (STAU1)-mediated mRNA decay (Gong \& Maquat 2011) and associate with lower levels of transcription (Faulkner et al. 2009), and an Alu repeat in the 3' region of the human growth hormone influences it's transcription rate (Trujillo et al. 2006). Of particular interest to the scenario in the human IL18RI gene, where the Alu insert occurs downstream of the 3' UTR, is a similar situation in the human APOA2 gene; in that case an Alu insert 305 nucleotides downstream of the polyadenylation signal of the APOA2 gene (Knott et al. 1985) (compared to 79 nucleotides from polyadenylation signal to 5' TSD in human type II IL18R1) contains an SNP (rs12143180) leading to a MspI restriction polymorphism which is associated with lipoprotein levels (Civeira et al. 1992). These findings provide an example of an Alu element downstream of a gene regulating phenotype, and raise the possibility that the Alu element downstream of the human type II IL18RI transcript could influence its transcription. Alu elements can also be subject to methylation (Xiang et al. 2010; Byun et al. 2012), and differential methylation could conceivably form a mechanism by which type II IL-18r1 transcription could be limited to select cells or stages of cellular development. If this $A l u$ element does play a role in the regulation of type II ILI8RI transcription in humans, the lack of 
an equivalent $A l u$ element in commonly used rodent laboratory animals suggests that this may form an important point of difference between IL-18 function in humans and rodents, and limit the generalization of results between these species.

One limitation of our study is that we have not verified whether human and rat type II IL18RI/IL18rl transcripts are indeed translated into type II IL-18R $\alpha$ proteins. This has also not been shown yet for murine type II IL18rl transcripts. Antibodies for the detection of IL-18R $\alpha$ will need to be carefully validated for their respective binding abilities of type I and the putative type II IL-18R $\alpha$ proteins in order to enable experimentation into their presence in different tissue types. In addition, from our results the source of the identified type II ILI8RI transcripts has not been assessed in terms of examining specific cell types expressing this mRNA transcript. The type I reference $I L 18 R I$ transcript is expressed in a variety of cell types, and identifying which of these also express type II IL18RI will be an important step in determining the physiological role of type II IL18R1. Neither have we specifically identified the transcription start or termination sites for human or rat type II IL18RI/IL18r1 transcripts. However, based on the cDNA record BG542027.1, alignment with mouse type II IL18r1, and the site of a putative polyadenylation signal, we conclude that the transcription termination site for human type II IL18RI occurs 357 bp into the inserted intron sequence (see Figure 6).

\section{Conclusions:}

In conclusion, we have identified alternative transcripts of the human and rat ILI RRI/ILI $8 \mathrm{r} 1$ genes, analogous to the previously reported type II IL18rI transcript in the mouse (Alboni et al. 2009). These transcripts are likely to produce truncated proteins lacking most of the intracellular domain, which would be expected to result in altered signalling properties and thus may influence IL-18 activity in vivo. We also provide evidence that transcription of homologous intron regions in other species could give rise to similar truncated transcripts, and that these genetic regions shown signs of selection pressure, indicating that this may be a mechanism of regulating IL-18 signalling which is conserved across different branches of the evolutionary tree. Given the apparent similarity between predicted protein sequences for these truncated IL18R $\alpha$ isoforms and IL1R2, and hence a similar predicted function as a receptor which fails to elicit intracellular signalling, we suggest adopting the nomenclature IL18R $\alpha 2$ to refer to these splice variant isoforms. 


\section{References:}

Adachi O, Kawai T, Takeda K, Matsumoto M, Tsutsui H, Sakagami M, Nakanishi K \& Akira S, 1998. Targeted disruption of the MyD88 gene results in loss of IL-1- and IL-18mediated function. Immunity, 9(1): 143-150.

Alboni S, Cervia D, Ross B, Montanari C, Gonzalez ASS, Sanchez-Alavez M, Marcondes MCGC, De Vries D, Sugama S, Brunello N, Blom J, Tascedda F \& Conti B, 2009. Mapping of the full length and the truncated interleukin-18 receptor alpha in the mouse brain. Journal of Neuroimmunology, 214(1-2): 43-54.

Amin MA, Rabquer BJ, Mansfield PJ, Ruth JH, Marotte H, Haas CS, Reamer EN \& Koch AE, 2010. Interleukin 18 induces angiogenesis in vitro and in vivo via Src and Jnk kinases. Annals of the Rheumatic Diseases, 69(12): 2204-12.

Bakri Hassan A, Rönnelid J, Gunnarsson I, Karlsson G, Berg L \& Lundberg I, 1998. Increased serum levels of immunoglobulins, C-reactive protein, type 1 and type 2 cytokines in patients with mixed connective tissue disease. Journal of Autoimmunity, 11(5): 503508.

Batzer MA \& Deininger PL, 2002. Alu repeats and human genomic diversity. Nature Reviews Genetics, 3(5): 370-379.

Berg MG, Singh LN, Younis I, Liu Q, Pinto AM, Kaida D, Zhang Z, Cho S, Sherrill-Mix S, Wan L \& Dreyfuss G, 2012. U1 snRNP determines mRNA length and regulates isoform expression. Cell, 150(1): 53-64.

Bergthorsson U, Andersson DI \& Roth JR, 2007. Ohno's dilemma: evolution of new genes under continuous selection. Proceedings of the National Academy of Sciences of the United States of America, 104(43): 17004-17009.

Bhangale TR, Rieder MJ, Livingston RJ \& Nickerson DA, 2005. Comprehensive identification and characterization of diallelic insertion-deletion polymorphisms in 330 human candidate genes. Human Molecular Genetics, 14(1): 59-69.

Bodolay E, Aleksza M, Antal-Szalmás P, Végh J, Szodoray P, Soltész P, Szegedi A \& Szekanecz Z, 2002. Serum cytokine levels and type 1 and type 2 intracellular T cell 
cytokine profiles in mixed connective tissue disease. Journal of Rheumatology, 29(10): $2136-2142$.

Boraschi D, Lucchesi D, Hainzl S, Leitner M, Maier E, Mangelberger D, Oostingh GJ, Pfaller T, Pixner C, Posselt G, Italiani P, Nold MF, Nold-Petry CA, Bufler P \& Dinarello CA, 2011. IL-37: a new anti-inflammatory cytokine of the IL-1 family. European Cytokine Network, 22(3): 127-147.

Breda L, Nozzi M, De Sanctis S \& Chiarelli F, 2010. Laboratory tests in the diagnosis and follow-up of pediatric rheumatic diseases: an update. Seminars in Arthritis and Rheumatism, 40(1): 53-72.

Byun H-M, Nordio F, Coull BA, Tarantini L, Hou L, Bonzini M, Apostoli P, Bertazzi PA \& Baccarelli A, 2012. Temporal stability of epigenetic markers: sequence characteristics and predictors of short-term DNA methylation variations. PLOS ONE, 7(6): e39220.

Chandrasekar B, Mummidi S, Valente AJ, Patel DN, Bailey SR, Freeman GL, Hatano M, Tokuhisa T \& Jensen LE, 2005. The pro-atherogenic cytokine interleukin-18 induces CXCL16 expression in rat aortic smooth muscle cells via MyD88, interleukin-1 receptor-associated kinase, tumor necrosis factor receptor-associated factor 6, c-Src, phosphatidylinositol 3-kinase, Akt, c-Jun N-terminal kinase, and activator protein-1 signaling. Journal of Biological Chemistry, 280(28): 26263-26277.

Civeira F, Genest J, Pocovi M, Salem DN, Herbert PN, Wilson PW, Schaefer EJ \& Ordovas JM, 1992. The MspI restriction fragment length polymorphism 3' to the apolipoprotein A-II gene: relationships with lipids, apolipoproteins, and premature coronary artery disease. Atherosclerosis, 92(2-3): 165-176.

Colotta F, Dower SK, Sims JE \& Mantovani A, 1994. The type II 'decoy’ receptor: a novel regulatory pathway for interleukin-1. Immunology Today, 15(12): 562-566.

Cordaux R \& Batzer MA, 2009. The impact of retrotransposons on human genome evolution. Nature Reviews Genetics, 10(10): 691-703.

Dinarello C, 2009. Immunological and inflammatory functions of the interleukin-1 family. Annual Review of Immunology, 27: 519-550. 
Dinarello CA, 2006. Interleukin 1 and interleukin 18 as mediators of inflammation and the aging process. American Journal of Clinical Nutrition, 83(2): 447S-455S.

Dinarello CA, 1998. Interleukin-1 beta, interleukin-18, and the interleukin-1 beta converting enzyme. Annals of the New York Academy of Sciences, 856: 1-11.

Dinarello CA \& Fantuzzi G, 2003. Interleukin-18 and host defense against infection. Journal of Infectious Diseases, 187(Suppl 2): S370-84.

Drummond A, Ashton B, Buxton S, Cheung M, Cooper A, Druan C, Field M, Heled J, Kearse M, Markowitz S, Moir R, Stones-Havas S, Sturrock S, Thierer T \& Wilson A, 2012. Geneious v5.6. Available at: http://www.geneious.com [Accessed July 23, 2012].

Dunne A \& O’Neill LAJ, 2003. The interleukin-1 receptor/Toll-like receptor superfamily: signal transduction during inflammation and host defense. Science's STKE: Signal Transduction Knowledge Environment, 2003(171): re3.

Ebihara M, Ohba H, Ohno S \& Yoshikawa T, 2002. Genomic organization and promoter analysis of the human nicotinic acetylcholine receptor alpha6 subunit (CHNRA6) gene: Alu and other elements direct transcriptional repression. Gene, 298(1): 101-108.

European Bioinformatics Institute, 2011. EMBL European Bioinformatics Institute. Available at: http://www.ebi.ac.uk [Accessed September 28, 2011].

Faulkner GJ, Kimura Y, Daub CO, Wani S, Plessy C, Irvine KM, Schroder K, Cloonan N, Steptoe AL, Lassmann T, Waki K, Hornig N, Arakawa T, Takahashi H, Kawai J, Forrest ARR, Suzuki H, Hayashizaki Y, Hume DA, Orlando V, Grimmond SM \& Carninci P, 2009. The regulated retrotransposon transcriptome of mammalian cells. Nature Genetics, 41(5): 563-571.

Favilli F, Anzilotti C, Martinelli L, Quattroni P, De Martino S, Pratesi F, Neumann D, Beermann S, Novick D, Dinarello CA, Boraschi D \& Migliorini P, 2009. IL-18 activity in systemic lupus erythematosus. Annals of the New York Academy of Sciences, 1173: 301-309. 
Feschotte C, 2008. Transposable elements and the evolution of regulatory networks. Nature Reviews Genetics, 9(5): 397-405.

GlaxoSmithKline, 2008. Combination study of SB-485232 (interleukin 18) and doxil for advanced stage epithelial ovarian cancer. ClinicalTrials.gov identifier: NCT00659178. Available at: http://www.clinicaltrials.gov/ct2/show/NCT00659178 [Accessed July 16, 2012].

Le Goff W, Guerin M, Chapman MJ \& Thillet J, 2003. A CYP7A promoter binding factor site and Alu repeat in the distal promoter region are implicated in regulation of human CETP gene expression. Journal of Lipid Research, 44(5): 902-910.

Gong C \& Maquat LE, 2011. IncRNAs transactivate STAU1-mediated mRNA decay by duplexing with 3' UTRs via Alu elements. Nature, 470(7333): 284-288.

Hambor JE, Mennone J, Coon ME, Hanke JH \& Kavathas P, 1993. Identification and characterization of an Alu-containing, T-cell-specific enhancer located in the last intron of the human CD8 alpha gene. Molecular and Cellular Biology, 13(11): 7056-7070.

Hivert M, Sun Q, Shrader P, Mantzoros C, Meigs J \& Hu F, 2009. Circulating IL-18 and the risk of type 2 diabetes in women. Diabetologia, 52(10): 2101-2108.

Ho E, Fard A \& Maisel A, 2010. Evolving use of biomarkers for kidney injury in acute care settings. Current Opinion in Critical Care, 16(5): 399-407.

Hwu HR, Roberts JW, Davidson EH \& Britten RJ, 1986. Insertion and/or deletion of many repeated DNA sequences in human and higher ape evolution. Proceedings of the National Academy of Sciences of the United States of America, 83(11): 3875-3879.

Jacobsen BM, Jambal P, Schittone SA \& Horwitz KB, 2009. ALU repeats in promoters are position-dependent co-response elements (coRE) that enhance or repress transcription by dimeric and monomeric progesterone receptors. Molecular Endocrinology (Baltimore, Md.), 23(7): 989-1000.

Jefferis BJ, Papacosta O, Owen CG, Wannamethee SG, Humphries SE, Woodward M, Lennon LT, Thomson A, Welsh P, Rumley A, Lowe GDO \& Whincup PH, 2011. Interleukin 18 
and coronary heart disease: prospective study and systematic review. Atherosclerosis, 217(1): 227-233.

Kaida D, Berg MG, Younis I, Kasim M, Singh LN, Wan L \& Dreyfuss G, 2010. U1 snRNP protects pre-mRNAs from premature cleavage and polyadenylation. Nature, 468(7324): 664-668.

Kattah NH, Kattah MG \& Utz PJ, 2010. The U1-snRNP complex: structural properties relating to autoimmune pathogenesis in rheumatic diseases. Immunological Reviews, 233(1): 126-145.

Khan JA, Brint EK, O’Neill LAJ \& Tong L, 2004. Crystal structure of the Toll/interleukin-1 receptor domain of human IL-1RAPL. Journal of Biological Chemistry, 279(30): 31664-31670.

Knott TJ, Wallis SC, Robertson ME, Priestley LM, Urdea M, Rall LB \& Scott J, 1985. The human apolipoprotein AII gene: structural organization and sites of expression. Nucleic Acids Research, 13(17): 6387-6398.

Laperriere D, Wang T-T, White JH \& Mader S, 2007. Widespread Alu repeat-driven expansion of consensus DR2 retinoic acid response elements during primate evolution. $B M C$ Genomics, 8(1): 23.

Lewis E \& Dinarello C, 2006. Responses of IL-18- and IL-18 receptor-deficient pancreatic islets with convergence of positive and negative signals for the IL-18 receptor. Proceedings of the National Academy of Sciences of the United States of America, 103(45): 16852-16857.

Lindblad-Toh K, Garber M, Zuk O, Lin MF, Parker BJ, Washietl S, Kheradpour P, Ernst J, Jordan G, Mauceli E, Ward LD, Lowe CB, Holloway AK, Clamp M, Gnerre S, Alfoldi J, Beal K, Chang J, Clawson H, Cuff J, Di Palma F, Fitzgerald S, Flicek P, Guttman M, Hubisz MJ, Jaffe DB, Jungreis I, Kent WJ, Kostka D, Lara M, Martins AL, Massingham T, Moltke I, Raney BJ, Rasmussen MD, Robinson J, Stark A, Vilella AJ, Wen J, Xie X, Zody MC, Worley KC, Kovar CL, Muzny DM, Gibbs RA, Warren WC, Mardis ER, Weinstock GM, Wilson RK, Birney E, Margulies EH, Herrero J, Green ED, Haussler D, Siepel A, Goldman N, Pollard KS, Pedersen JS, Lander ES \& Kellis M, 2011. A high- 
resolution map of human evolutionary constraint using 29 mammals. Nature, 478(7370): 476-482.

Matsunaga H, Hokari R, Ueda T, Kurihara C, Hozumi H, Higashiyama M, Okada Y, Watanabe C, Komoto S, Nakamura M, Kawaguchi A, Nagao S, Sekiyama A \& Miura S, 2011. Physiological stress exacerbates murine colitis by enhancing proinflammatory cytokine expression that is dependent on IL-18. American Journal of Physiology. Gastrointestinal and Liver Physiology, 301(3): G555-64.

Ma Y, Zhang B, Tang R-K, Liu Y \& Peng G-G, 2012. Interleukin-18 promoter polymorphism and asthma risk: a meta-analysis. Molecular Biology Reports, 39(2): 1371-6.

Merkhofer EC \& Johnson TL, 2012. U1 snRNA rewrites the 'script'. Cell, 150(1): 9-11.

National Center for Biotechnology Information, 2010. Primer-BLAST primer designing tool. Available at: http://www.ncbi.nlm.nih.gov/tools/primer-blast/index.cgi [Accessed December 2, 2010].

Nold-Petry CA, Nold MF, Nielsen JW, Bustamante A, Zepp JA, Storm KA, Hong J-W, Kim SH \& Dinarello CA, 2009. Increased cytokine production in interleukin-18 receptor $\alpha-$ deficient cells is associated with dysregulation of suppressors of cytokine signaling. Journal of Biological Chemistry, 284(38): 25900-25911.

Novick D, Kim SH, Fantuzzi G, Reznikov LL, Dinarello CA \& Rubinstein M, 1999. Interleukin-18 binding protein: a novel modulator of the Th1 cytokine response. Immunity, 10(1): 127-136.

Pandey R, Mandal AK, Jha V \& Mukerji M, 2011. Heat shock factor binding in Alu repeats expands its involvement in stress through an antisense mechanism. Genome Biology, 12(11): R117.

RepeatMasker, 2012. human ALU subfamilies. Available at: http://www.repeatmasker.org/AluSubfamilies/humanAluSubfamilies.html [Accessed July 16, 2012]. 
Rivas MA, Beaudoin M, Gardet A, Stevens C, Sharma Y, Zhang CK, Boucher G, Ripke S, Ellinghaus D, Burtt N, Fennell T, Kirby A, Latiano A, Goyette P, Green T, Halfvarson J, Haritunians T, Korn JM, Kuruvilla F, Lagacé C, Neale B, Lo KS, Schumm P, Törkvist L, Dubinsky MC, Brant SR, Silverberg MS, Duerr RH, Altshuler D, Gabriel S, Lettre G, Franke A, D'Amato M, McGovern DPB, Cho JH, Rioux JD, Xavier RJ \& Daly MJ, 2011. Deep resequencing of GWAS loci identifies independent rare variants associated with inflammatory bowel disease. Nature Genetics, 43(11): 1066-1073.

Sahar S, Dwarakanath R, Reddy M, Lanting L, Todorov I \& Natarajan R, 2005. Angiotensin II enhances interleukin-18 mediated inflammatory gene expression in vascular smooth muscle cells: a novel cross-talk in the pathogenesis of atherosclerosis. Circulation Research, 96(10): 1064-1071.

Schrago CG \& Russo CAM, 2003. Timing the origin of New World monkeys. Molecular Biology and Evolution, 20(10): 1620-1625.

Seenu Reddy V, Prabhu SD, Mummidi S, Valente AJ, Venkatesan B, Shanmugam P, Delafontaine P \& Chandrasekar B, 2010. Interleukin-18 induces EMMPRIN expression in primary cardiomyocytes via JNK/Sp1 signaling, and MMP9 in part via EMMPRIN, and through AP-1 and NF-kB activation. American Journal of Physiology. Heart and Circulatory Physiology, 299(4): H1242-54.

Siegmund B, 2010. Interleukin-18 in intestinal inflammation: friend and foe? Immunity, 32(3): 300-302.

Slack JL, Schooley K, Bonnert TP, Mitcham JL, Qwarnstrom EE, Sims JE \& Dower SK, 2000. Identification of two major sites in the type I interleukin-1 receptor cytoplasmic region responsible for coupling to pro-inflammatory signaling pathways. Journal of Biological Chemistry, 275(7): 4670-4678.

Smit A, Hubley R \& Green P, 2012. RepeatMasker Open-3.0. 1996-2010. Available at: http://www.repeatmasker.org/ [Accessed July 13, 2012].

Smyth DJ, Plagnol V, Walker NM, Cooper JD, Downes K, Yang JH, Howson JM, Stevens H, Mcmanus R, Wijmenga C, Heap GA, Dubois PC, Clayton DG, Hunt KA, van Heel DA 
\& Todd JA, 2008. Shared and distinct genetic variants in type 1 diabetes and celiac disease. New England Journal of Medicine, 359(26): 2767-77.

Specialty Feeds Pty Ltd., 2012. Meat free rat and mouse cubes. Available at: http://www.specialtyfeeds.com.au/data/meat_free_r\&m.pdf [Accessed August 15, 2012].

Srivastava S, Salim N \& Robertson MJ, 2010. Interleukin-18: biology and role in the immunotherapy of cancer. Current Medicinal Chemistry, 17(29): 3353-3357.

Steiper ME \& Young NM, 2006. Primate molecular divergence dates. Molecular Phylogenetics and Evolution, 41(2): 384-394.

Strausberg RL, Feingold EA, Grouse LH, Derge JG, Klausner RD, Collins FS, Wagner L, Shenmen CM, Schuler GD, Altschul SF, Zeeberg B, Buetow KH, Schaefer CF, Bhat NK, Hopkins RF, Jordan H, Moore T, Max SI, Wang J, Hsieh F, Diatchenko L, Marusina K, Farmer AA, Rubin GM, Hong L, Stapleton M, Soares MB, Bonaldo MF, Casavant TL, Scheetz TE, Brownstein MJ, Usdin TB, Toshiyuki S, Carninci P, Prange C, Raha SS, Loquellano NA, Peters GJ, Abramson RD, Mullahy SJ, Bosak SA, McEwan PJ, McKernan KJ, Malek JA, Gunaratne PH, Richards S, Worley KC, Hale S, Garcia AM, Gay LJ, Hulyk SW, Villalon DK, Muzny DM, Sodergren EJ, Lu X, Gibbs RA, Fahey J, Helton E, Ketteman M, Madan A, Rodrigues S, Sanchez A, Whiting M, Madan A, Young AC, Shevchenko Y, Bouffard GG, Blakesley RW, Touchman JW, Green ED, Dickson MC, Rodriguez AC, Grimwood J, Schmutz J, Myers RM, Butterfield YSN, Krzywinski MI, Skalska U, Smailus DE, Schnerch A, Schein JE, Jones SJM \& Marra MA, 2002. Generation and initial analysis of more than 15,000 full-length human and mouse cDNA sequences. Proceedings of the National Academy of Sciences of the United States of America, 99(26): 16899-16903.

The Andersons, Inc., 2012. The Andersons Lab Bedding Products. Bed-o'Cobs ${ }^{\circledR} 1 / 4$ ". Available at: http://www.andersonslabbedding.com/cob-products/bed-ocobs-4b/ [Accessed August 15, 2012].

Thorand B, Kolb H, Baumert J, Koenig W, Chambless L, Meisinger C, Illig T, Martin S \& Herder C, 2005. Elevated levels of interleukin-18 predict the development of type 2 
diabetes: results from the MONICA/KORA Augsburg Study, 1984-2002. Diabetes, 54(10): 2932-2938.

Trujillo MA, Sakagashira M \& Eberhardt NL, 2006. The human growth hormone gene contains a silencer embedded within an Alu repeat in the 3 '-flanking region. Molecular Endocrinology, 20(10): 2559-2575.

University of Otago, 2012. Genetic Analysis Services. Available at: http://gas.otago.ac.nz/ [Accessed July 4, 2012].

Vansant G \& Reynolds WF, 1995. The consensus sequence of a major Alu subfamily contains a functional retinoic acid response element. Proceedings of the National Academy of Sciences of the United States of America, 92(18): 8229-8233.

Wang X, Fan J, Liu D, Fu S, Ingvarsson S \& Chen H, 2011. Spreading of Alu methylation to the promoter of the MLH1 gene in gastrointestinal cancer. PloS ONE, 6(10): e25913.

Watanabe M, Goto N, Watanabe Y, Nishiguchi S, Shimada K, Yasunga T \& Yamanishi H, 2005. Evolution of interleukin-18 binding proteins and interleukin-1 receptor, type II proteins. International Journal of Molecular Medicine, 15(4): 561-566.

Watanabe M, Kaneko H, Shikano H, Aoki M, Sakaguchi H, Matsui E, Inoue R, Kato Z, Kasahara K, Fukutomi O, Kondo T \& Kondo N, 2002. Predominant expression of 950delCAG of IL-18R alpha chain cDNA is associated with reduced IFN-gamma production and high serum IgE levels in atopic Japanese children. Journal of Allergy and Clinical Immunology, 109(4): 669-675.

Xiang S, Liu Z, Zhang B, Zhou J, Zhu B-D, Ji J \& Deng D, 2010. Methylation status of individual $\mathrm{CpG}$ sites within Alu elements in the human genome and Alu hypomethylation in gastric carcinomas. BMC Cancer, 10: 44.

Xu Y, Tao X, Shen B, Horng T, Medzhitov R, Manley JL \& Tong L, 2000. Structural basis for signal transduction by the Toll/interleukin-1 receptor domains. Nature, 408(6808): 111115. 


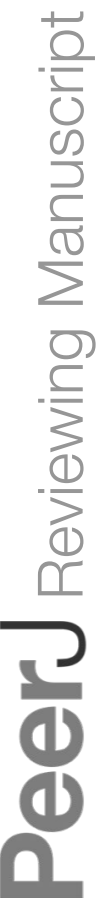

PeerJ reviewing PDF | (v2014:05:2188:1:1:NEW 12 Aug 2014) 


\section{Table 1 (on next page)}

Primer details for amplification of putative type II IL-18r1 transcripts in rat and human samples. 


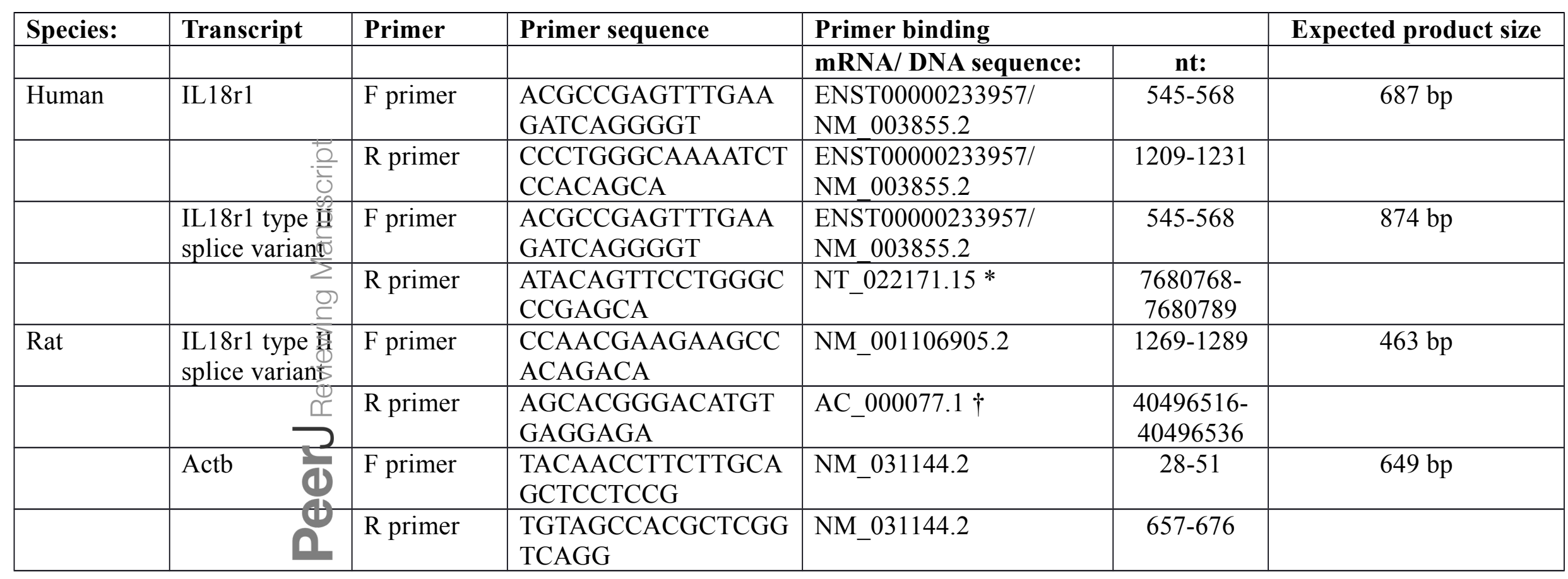

* Alternative R primer genomic coordinates: GRCh37, chromosome 2: 103006939-103006960

$\dagger$ Alternative R primer genomic coordinates: RGSC3.4, chromosome 9: 39652714-39652734 


\section{Figure 1}

Schematic diagram of $I L 18 R 1$ reference sequence and aligned expressed sequence tags

IL18R1 reference sequence (ENST00000233957/NM_003855.2) intron-exon structure aligned with three identified expressed sequence tags containing portions of intron 8-9. Shown above in boxed region is the expected protein coding sequence of a putative human IL18R1 splice variant incorporating intron 8-9 of ENST00000233957. Underlined nucleotides indicate those from the preceding exon 8 . Codons are indicated by alternate grey shading of nucleotides. Incorporation of intron 8-9 would be expected to translate into a protein with a novel 22 amino acid C-terminal followed by a stop codon. First nucleotide shown in boxed region is nt 1132 from ENST00000233957/NM_003855.2, first amino acid is residue 370 from ENSP00000233957.1/NP_003846.1.

ᄂ $==ニ \pm---$

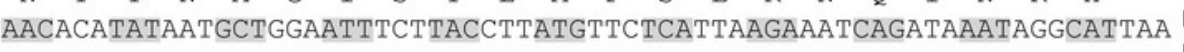




\section{Table 2 (on next page)}

Analysis of Sanger sequencing products for RT-PCR of human (A) and rat (B) IL-18r1 type II transcripts.

Sequencing products were compared with predicted IL-18r1 type II sequences derived from reference human and rat genes using Geneious Basic (Drummond et al. 2012). For human sequences, two deviations from the reference sequence were noted: rs 1035130 , and a nt 950 CAG deletion as reported by Watanabe et al. (Watanabe et al., 2002). For rat sequences, a presumed SNP was identified which was consistent across both samples and in both sequencing directions at high read quality, present at nucleotide 39,652,571 of chromosome 9 (G>A; rat genome Baylor 3.4/rn4 build). In both cases predicted sequences were edited prior to alignment to account for these variations in the tables below. Raw chromatograms are included in the Supporting Information. 
A.

\begin{tabular}{|l|l|c|c|c|c|c|c|}
\hline & & \multicolumn{2}{|c|}{ Identities } & \multicolumn{2}{c|}{ Positives } & \multicolumn{2}{c|}{ Gaps } \\
\hline Polymerase & $\begin{array}{l}\text { Sequencing } \\
\text { primer }\end{array}$ & $\mathbf{\%}$ & $\mathbf{n}$ & $\mathbf{\%}$ & $\mathbf{n}$ & $\mathbf{\%}$ & $\mathbf{n}$ \\
\hline Platinum Taq & forward & 86 & $753 / 875$ & 94 & $826 / 875$ & 3 & $32 / 875$ \\
\hline & reverse 0 & 88 & $773 / 877$ & 94 & $832 / 877$ & 3 & $32 / 877$ \\
\hline Accuprime Taq & forward & 79 & $699 / 878$ & 89 & $788 / 878$ & 4 & $36 / 878$ \\
\hline & reverse & 83 & $736 / 877$ & 91 & $805 / 877$ & 3 & $33 / 877$ \\
\hline
\end{tabular}

B.

\begin{tabular}{|l|l|c|c|c|c|c|c|}
\hline & \multicolumn{2}{|c|}{ Identities } & \multicolumn{2}{c|}{ Positives } & \multicolumn{2}{c|}{ Gaps } \\
\hline Sample & $\begin{array}{l}\text { Sequenging } \\
\text { primer }\end{array}$ & $\mathbf{\%}$ & $\mathbf{n}$ & $\mathbf{\%}$ & $\mathbf{n}$ & $\mathbf{\%}$ & $\mathbf{n}$ \\
& forwar & 91 & $427 / 466$ & 92 & $429 / 466$ & 6 & $31 / 466$ \\
\hline Rat B & rever & 91 & $427 / 466$ & 91 & $428 / 466$ & 7 & $35 / 466$ \\
\hline Rat C & forward & 91 & $427 / 465$ & 92 & $430 / 465$ & 6 & $31 / 465$ \\
\hline & reverse & 90 & $423 / 467$ & 91 & $426 / 467$ & 7 & $37 / 467$ \\
\hline
\end{tabular}




\section{Figure 2}

Schematic diagram of $I L 18 R 1$ reference sequence and aligned expressed sequence tags

IL18R1 cDNA from human blood was amplified by PCR using two polymerases, Platinum and Accuprime Taq as indicated, using the primer pairs shown in Table 1 to amplify the IL18R1 reference transcript ('IL18R1', expected product size 687 bp) or predicted human type II IL18R1 splice variant ('type II', expected product size 847 bp). 'RT+' and 'RT-' indicate PCR template generated with the addition of reverse transcriptase or without, respectively. Left hand lane shows $100 \mathrm{bp}$ DNA ladder; brighter band towards the centre of the gel is $600 \mathrm{bp}$. 

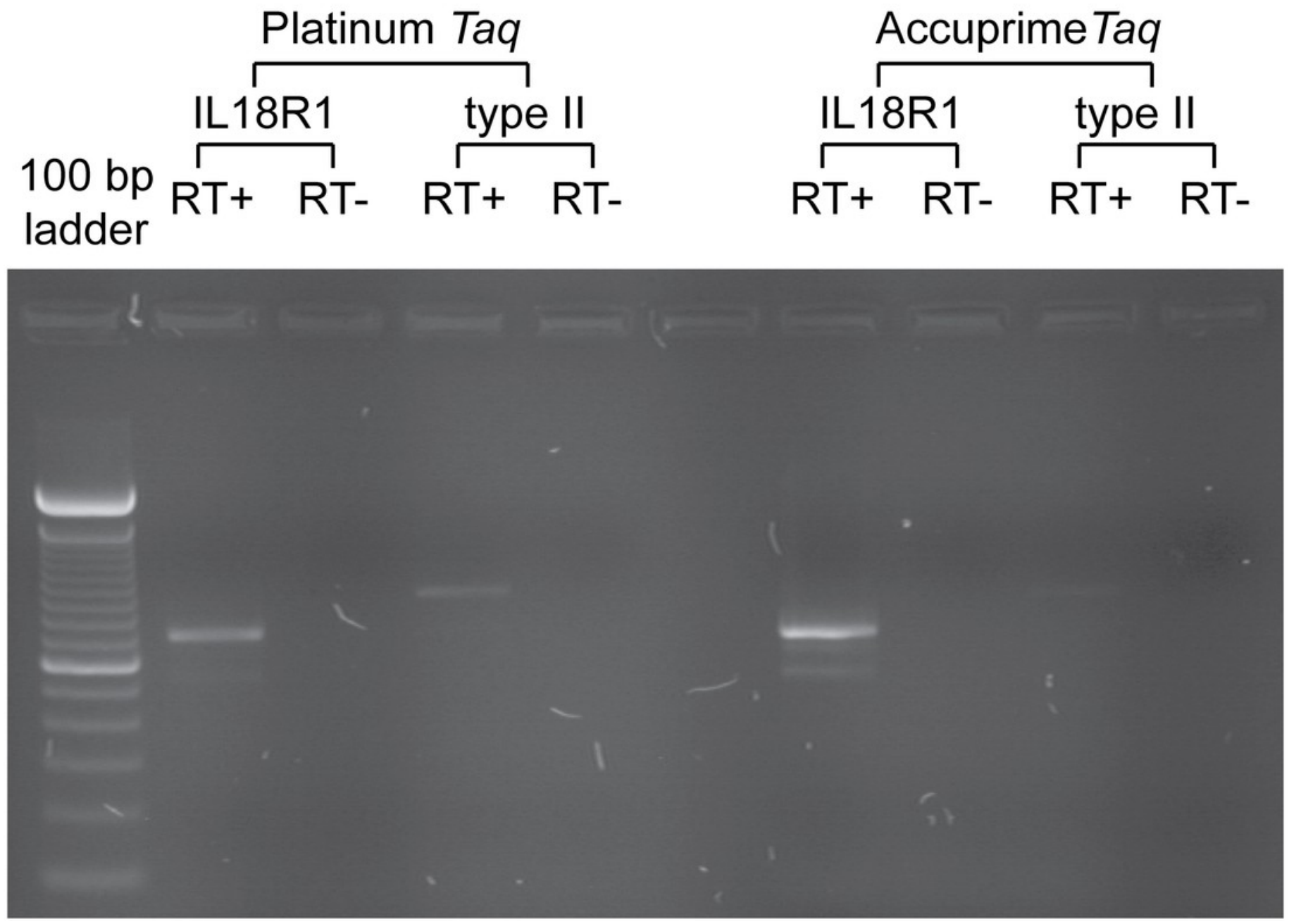


\section{Figure 3}

Comparison of human type I and type II IL18R1.

A. C-terminal ends of human IL-18R $\alpha$ and predicted type II IL-18R $\alpha$ amino acid sequences.

First amino acid, underlined, corresponds to residue 370 from

ENSP00000233957.1/NP_003846.1. Shown in red is the amino acid at which the IL-18R $\alpha$ and predicted type II IL-18R $\alpha$ sequences diverge, which is encoded across an exon/exon and exon/intron boundary in the case of the reference sequence and predicted type II sequence, respectively. Between the two sequences similar residues are shown, with the region of IL$18 R \propto$ corresponding to 'Box 1' of the TIR domain (Dunne \& O'Neill, 2003) indicated. B shows pairwise alignment by EMBOSS Water (European Bioinformatics Institute, 2011) of the nucleotides from exon 9 of the human IL18R1 reference sequence (ENST00000233957/NM_003855.2) with those of intron 8-9. Codons are indicated by alternating grey shading, with the initial $\mathrm{G}$ nucleotide shown in brackets being the final nucleotide from exon 8 (nt 1135 of ENST00000233957/NM_003855.2). Above and below the respective sequences are shown the corresponding amino acid sequences. 
A

Human IL-18Ra reference sequence

Predicted human IL-18R $\alpha$ type II sequence

\section{TIR box 1}

TEKTYDAFVSYL
TECRPENGEEHTFAV .... etc
T-GNTYNAGISYLIFSLRNQINRH

\section{B}
--D--G--K--T--Y--D--A-------F--V--S--Y--L-------------K--
reference exon 9 1 (G) ATGGAAAAACATATGATGCT----TTTGTGTCTTACCTAA---------AAG 39
intron 8-9 1 (G)---GTAACACATATAATGCTGGATT----TCTTACCTTATGTTCTCATTAAG 46
$-----\mathrm{G}--\mathrm{N}--\mathrm{T}--\mathrm{Y}--\mathrm{N}--\mathrm{A}--\mathrm{G}--\mathrm{I}------\mathrm{S}--\mathrm{Y}--\mathrm{L}--\mathrm{M}--\mathrm{F}--\mathrm{S}--\mathrm{L}--\mathrm{R}$

$\mathrm{E}--\mathrm{C}--\mathrm{R}--\mathrm{P}--\mathrm{E}---\mathrm{N}--\mathrm{G}--\mathrm{E}--\mathrm{E}--\mathrm{H}----------\mathrm{T}--\mathrm{F}--\mathrm{A}--\mathrm{V}-$

reference exon 9 AATGCCGACCTGA-AAATGGAGAGGAGCA-------CACCTTTGCTGTG 80

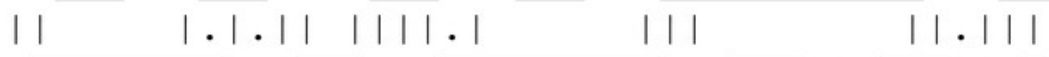

intron 8-9 AA-----ATCAGATAAATAG------GCATTAATCTTCATCTT------- 78

$-------N--Q--I--N--R--------H--s t$ 


\section{Figure 4}

Multiple sequence alignment of human IL-1 receptor family members

The predicted protein coding sequence of human type II IL-18R $\alpha$ aligned with IL-1 receptor family members. Shown are the amino acid residues surrounding the beginning of the TIR domain, where the sequence of type II IL-18R $\alpha$ diverges from the reference sequence. Boxed regions are the 'Box 1' and 'Box 2' motifs present in the TIR domain.

TIR box 1
TIR box 2

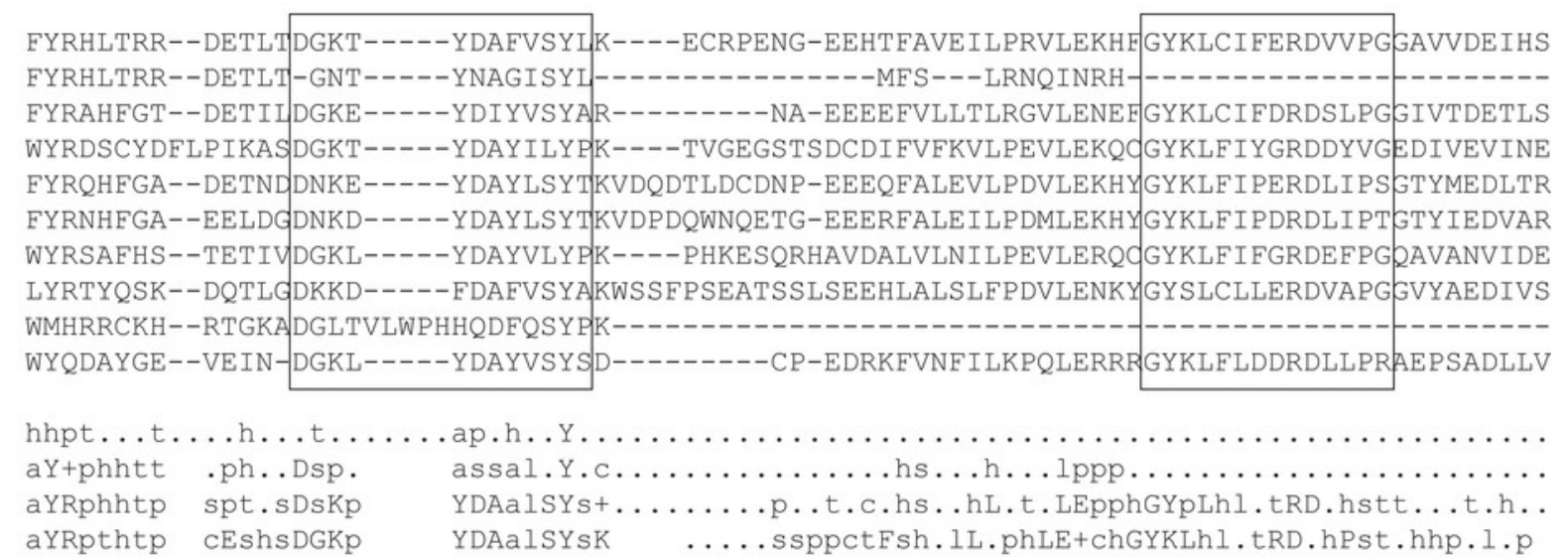




\section{Figure 5}

Multiple sequence alignment of putative type II IL-18R $\alpha$ C-terminal ends across multiple species.

Sequences are colour-coded as per MView (European Bioinformatics Institute, 2011): the human sequence is coloured according to residue properties, as indicated under 'Key', with residues from other species identical to human coloured with the same schema. Orangutan, Armadillo and Tarsier sequences are truncated by the indicated number of amino acids. Percentages reflect percent identity to human sequence as a reference. 
Human

Chimpanzee

Gorilla

Gibbon

Orangutan

Macaque

Dog

Bushbaby

Horse

Panda

Mouse Lemur

Rabbit

Megabat

Microbat

Tarsier

Armadillo

Pika

Dolphin

Elephant

Kangaroo Rat

Squirrel

Guinea Pig 22527

Guinea Pig 14114

Marmoset

Cow

Opossum

Anole Lizard

Turkey

Chicken

Tree Shrew

Rat

Mouse

Shrew

Lesser Hedgehog Tenrec

consensus $190 \%$

consensus / $80 \%$

consensus/70\%
$100.0 \%$

$100.0 \%$

$100.0 \%$

$95.5 \%$

$95.5 \%$

$86.4 \%$

$77.3 \%$

$77.3 \%$

$72.7 \%$

$72.7 \%$

$72.7 \%$

$63.6 \%$

$63.6 \%$

$63.6 \%$

$59.1 \%$

$59.1 \%$

$54.5 \%$

$50.0 \%$

$50.0 \%$

$50.0 \%$

$50.0 \%$

$40.9 \%$

$36.4 \%$

$36.4 \%$

$27.3 \%$

$27.3 \%$

$18.2 \%$

$18.2 \%$

$13.6 \%$

$13.6 \%$

$9.1 \%$

$9.1 \%$

$9.1 \%$

$9.1 \%$
1

।

GNTY-NAG ISYLMFSLRNQINRH

GNTY-NAGISYLMFSLRNQINRH

GNTY-NAGISYLMFSLRNQINRH

GNTY-NDGISYLMFSLRNQINRH

GNAY-NAGISYLMFSLRNQINRHKSSSYCDDI 21 aa

GNTY-NAGVISYLMSSLRNQINRR

GNEYWNP GISYLMASLRNQIKKH

GNNYRNASISFLMLSLRNQINYH

GNEHRINAGISYLMVISLRNOVKKH- - - - - - -

GNEYRNTGISYLMVISLRDQIKKH--------

GNNHRNAGISCLMLSLRNQIRNH

GNSYRNAG TSYFMLSLRNTIKKC - - - - - - -

GNKYHNPGISYSMVLLRNIIKKHYS S SYFDCY

GN $E$ YRNVGISYPMVISLGNLIKKH--------

GNSY-NTSMSYLMHSLRSQIQKYESSSYFDYI 26 aa

GNGCGRAGISYLRLSVREQIKKHSSSAYFDYV 70 aa

GNGYRINARTSYFMLILRNTIGNP--.-- - - -

GNECCHAGISYFTVLLRSYINKR---------

GNRYHNVGISYLMHS- - - - - - - - - - - -

GNRYHNAGTSYLMLAVFTMLNK---------

GNDCRNAGTSYEMMKLVNPIGKR--------

GNGCRDAGAFC FMLSWLNQTINES L SC------

GNGCRDAGDFCF I LSWLNOTNESLSC------

GNTY-NSGIPYHIV-----------------

GNECHINAGII LQFH----------------

GNIYRCTGISFLVSRIYSILS - - - - - - - -

GKTSW--GSTY--------------------

-------GRTWLMLTLK--------------

------- GMTWLTLTLK--------------

GNTL

GNLPL

GN

GNMLF-------------------------

GNR

GN

GNth...u.h.h.......

GNth.ssGhoahhh.hh.....

\section{Key:}

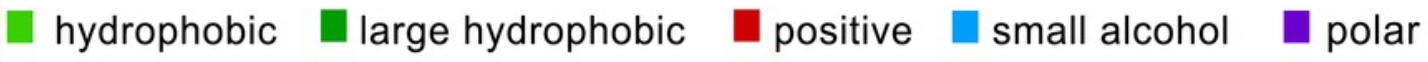




\section{Figure 6}

Alignment of homologous intron sequences from IL18R1 across a range of species.

A. When the reading frame is continued into the intron sequences, stop codons (red shading) are encountered shortly into the intron sequence, including a conserved stop codon position which resides within a region of high conservation (grey shading) as identified by LindbladToh et al. (Lindblad-Toh et al., 2011). Further downstream (B) an apparent conserved polyadenylation sequence (red shading, PolyA) is apparent, within a region of high conservation identified by Lindblad-Toh et al. (grey shading). A proposed transcription stop site (TSS) is indicated by the dotted line. 
1 Human

2 Gorilla

3 Chimpanzee

4 Gibbon

5 Orangutan

6 Macaque

7 Marmoset

8 Bushbaby

9 Horse

10 Mouse Lemur

11 Panda

12 Megabat

13 Dog

14 Rabbit

15 Tarsier

16 Squirrel

17 Microbat

18 Armadillo

19 Tree Shrew

20 Pika

21 elephant

22 Mouse

23 Rat

24 Cow

25 Dolphin

26 Kangaroo Rat

27 L. Hedgehog

28 Shrew

29 Opossum

30 Guinea_Pig_14114

31 Guinea_Pig_22527

32 Turkey

33 Chicken

34 Anole Lizard

consensus $/ 90$ \% consensus $/ 80$ \& consensus $/ 70 \%$

B

1 Human

2 Gorilla

3 Chimpanzee

4 Gibbon

5 orangutan

6 Macaque

7 Marmoset

8 Bushbaby

9 Horse

10 Mouse Lemur

11 Panda

12 Megabat

13 Dog

14 Rabbit

15 Tarsier

16 Squirre1

17 Microbat

18 Armadillo

19 Tree Shrew

20 Pika

21 Elephant

22 Mouse

23 Rat

24 Cow

25 Dolphin

26 Kangaroo Rat

$27 \mathrm{~L}$ Hedgehog Tenrec

28 Shrew

29 Opossum

30 Guinea Pig 14114

31 Guinea Pig 22527

32 Turkey

33 Chicken

34 Anole Lizard

consensus $/ 90$ ? consensus $/ 80 \%$ consensus/70\%

1

100.08 GTAACACATA---TAATG-CTGGAATTTCTTACCTTAT----GTTCTCATTAAGAAATCAGAT---AAA---TAGG

98.38 GTAACACATA---TAATG-CTGGAATTTCTTACCTTAT----GTTCTCATTAAGAAATCAGAT---AAA----TAGG

96.08 GTAACACATA---TAATG-CTGGAATTTCTTACCTTAT----GTTCTCATTAAGAAATCAGAT---AAA---TAGG

94.0\% GTAACACATA---TAATG-ATGGAATTTCTTACCTTAT----GTTCTCATTAAGAAATCAGAT---AAA---CAGA

93.28 GTAACGCATA---TAATG-CTGGAATTTCTTACCTTAT----GTTCTCATTAAGAAATCAGAT---AAA---TAGA

92.98 GTAACACATA---TAATG-CTGGGTTTCTTACCTTAT----GTCTTCTTTAAGAAATCAAAT---AAA---TAGA

81.08 GTAACACATA---TAATT-CTGGGATTCCTTATCATAT----AGTCEGAGTAAGAAATCAAAT---AAA----TAGA

67.6\% GTAACAACTACCGCAATG-CTTCGATTTCTTTTCTTAT----GCTTTCATTAAGAAACCAAAT---AAA---TTAT

65.68 GTAACAACTACCGAATG-CTTCGATTTCTTTTCTTAT----GCITCATTAAGAAACCAAAT---AAA---TTAT

$64.1 \%$ GTAACAATCATCGTAATG-CTGGGATTTCTTGTCTTAT----GCTCTCATTAAGAAACCAAAT----AAG---GAAC

63.88 GTAACGAATATCGTAATA-CTGGGATTTCTTATCTAAT--- GGTTTCATTAAGAGACCAAAT---AAA---GAAA

63.68 GTAACAAATATCATAATC-CTGGAATTTCTTATTCTAT----GGTTTTATTAAGAAACATAAT---AAA---GAAA

63.08 GTAACGAATATTGGAATC-CTGGGATTTCTTATCTCAT----GGCTTCATTAAGAAACCAAAT---AAA---GAAA

62.48 GTAACAGTTACCGAAATG-CTGGGACTTCTTATTTTAT----GCTCTCGTTAAGAAACACAAT---AAA----GAAC

59.98 GTAATTCATA---TAATA-CTAGCATGTCTTATCTTAT----GCACTCCTTAAGAAGTCAAAT---ACA---AAAG

59.68 GTAATGACTGTCGTAATG-CTGGGACTTCTTATTTCAT----GATGAAGTTAGTAAACCCAAT----AGG---GAAA

58.9\% GTAACGAATACCGGAATG-TTGGGATTTCTTATCCTAT----GGTTTCATTAGGAAACCTGAT----AAA----GAAA

56.18 GTAACGGATGTGGTCGTG-CTGGGATTTCTTATCTTAG----GCTTTCAGTAAGAGAGCAAAT----AAA----GAAA

53.98 GTAACA--CGTTA AAACG-CTGGGATTTCTTAACTTAC----GCTCTCCTGGGGAAACCAAATTAAAAAA---AAAAC-

50.68

50.68 GTAATGGTTACCGAAATG-CTAGGACTTCTTATTTTAT-"--GCTCTTGTTAAGAAACACAAT-"-TGG---AAAT

47.98 GTAATAGATATCATAATG-TTGGGATTTCTTATCTCAT----GCATTCATANAGAAACCAAAT---AAA---GAAA

47.18 GTAATA--TGCTGCTGTGA CAGGGGCACCCTAGCTCAT----GTTTTTGTGCCTGCACCCAGCAA-AGGAAAGAAA
$46.8 \%$ GTAATC--TGCCGCTGTGACAGGGACGTCCTAGCTCAT----GTTTTCATGCCTGCACCAAGT---AAAG--GACG

46.88
39.48
39

39.48
39.28
39

39.08 GTAACAGATATCACAATG-CTGGAACTTCTTATTTAATGCTGGCTGTCTTTACTATGCTCAAT---AAA--- TAA

35.68 GTAATAGGTARCATAATT-CTGGGG------GCTTCT----GTTTTCAGGAAGTAACCAAAT---AAG---GAGG

35.18 GTAACA--TGTTGTTCEG-ATTGAGTTTATTATCTTATTTATGGTTTCATTTAAAA--------AAACAATAAG

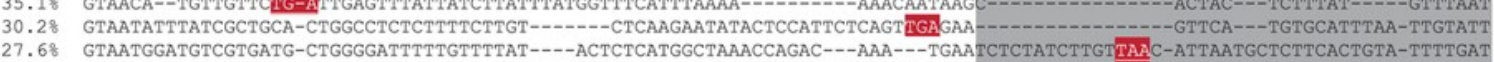

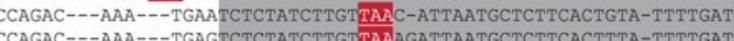

14.88 GTAGGACTTGGC-TAATG-CTGACATT--

14.88 GTAGGACI

$12.2 \%$ GTAAAACATC-------ATGGGGT

GAA

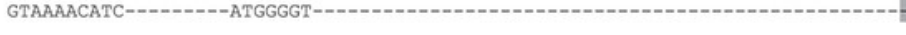

GAGA-DTACTTATIAA-

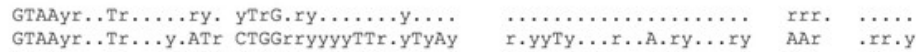

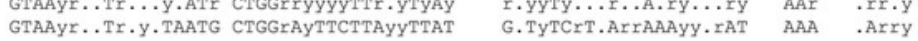

$\begin{array}{ll}\text { ry.rr } & \text { y.y.C.... } \ldots \ldots \text {. } \\ \text { rTTYA } & \text { TCTTC.УYTYA } . \text { T...AT }\end{array}$

ATTAA TCTTCATYTTA TT.TGAT

120

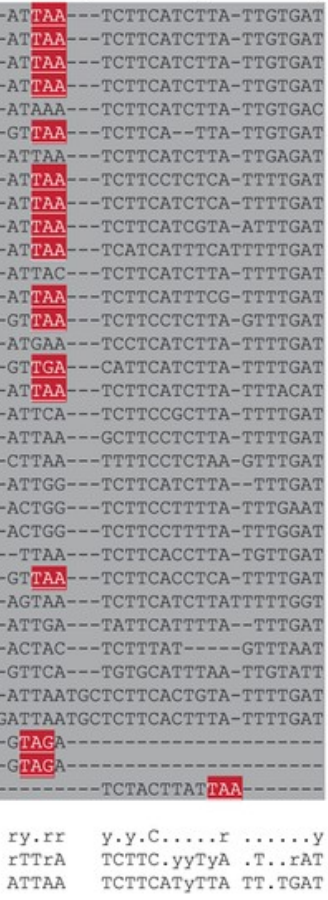

\section{Poly A TTS}

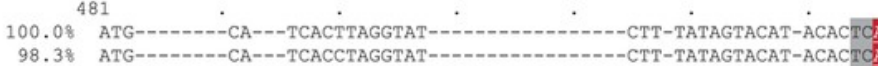

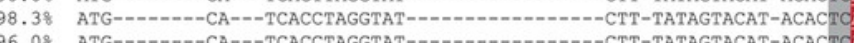

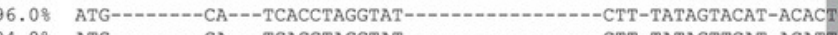

94.08 ATG-----CA---TCACCTAGGTAT-------CTT-TATAGTTCAT-ACAT

93.28 AAG----CA---TCACCTAGGTAT--

92.98 ATG----CA---TCACCTAGGTAT--

61.08 ACA-------GA---TCACCTTGGTAC-----1

65.78 ATA--------TA---CCATCTGGGCAC--------------CACGTACAGTGTGC-ACATT

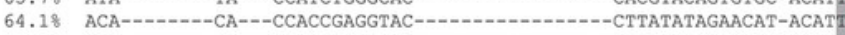

63.8\% ACA---1----CA---CAATCTGGGGAC---

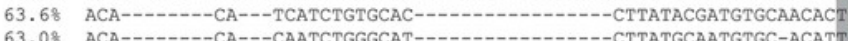

63.08 ACA-------CA---CAATCTGGGCAT----------1 62.48 GTA

59.98 CCG--------CGCCCCCTCCAGGTAC-----------TTTTTACAGTGCAT-GCACP

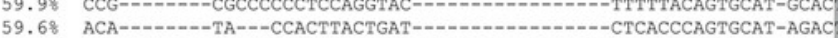

58.98 GCA--

56.18 ACA-------CA---CCATCEAGCTCC------1---

53.98 ACA------CA---TCACCCACATAA---

50.68 GTA------CA---AAATCTTAGTATTATATATACTAAGTGTGTATATATAATGCAT-ACAA

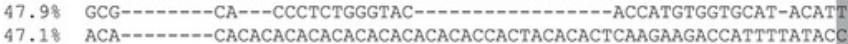

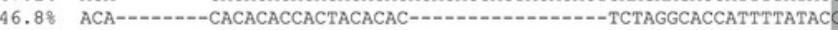

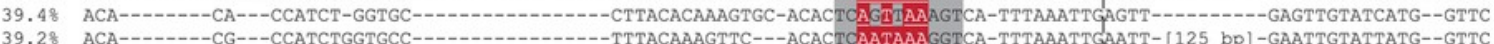

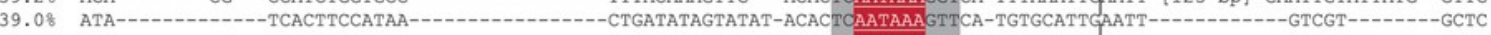

35.68 ACA--------TG---CCCTTTGGGAAC--------------CCCACATAGTGCAT-ATATTOAATAAAAGGTT-TAGACACTGAGTT---------TAACTGTATTATG--GTTT

35.18 ATA---------CTGTCTGGGTAA-----------TTTGTTCAGTTTGT-CAACTDAATAAATTTA--TTTGAGTTGAATT--------GTATTTT-------GCTG

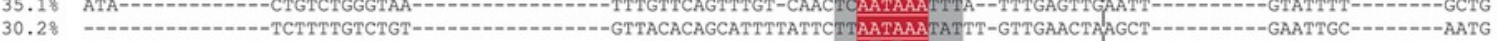

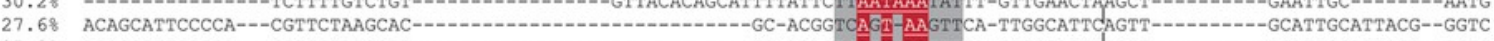

27.38 ACAGCTTTCCCCA---CCTTCTAAGCAC---_-

14.88 -

12.88

12.28

-AACTTTA-TCTGCTTTAAGTC-

-GAATTGCATTACG--GGTC

$\begin{array}{lll}\ldots r & \cdots & \ldots y y y \ldots r\end{array}$

$\begin{array}{lll}\underset{r}{r y r} & \because & \text { y.YYYTr.r.Ay } \\ \text { Ayr } & \ddot{C r} & \text { yCAYCTrrGyAy }\end{array}$

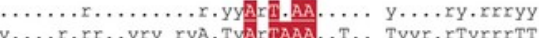

y....r.rr..yry ryA.TYArIAAA.. T.. TYYr.rTyrrrTT

a.m.

GrATTGT.Y.AY. $\quad$ rYTC 